2. Peel J, Funk D, Slinger P, Srinathan S, Kidane B. Positive end-expiratory pressure and recruitment maneuvers during one-lung ventilation: a systematic review and meta-analysis. J Thorac Cardiovasc Surg. 2020;160: 1112-22.e3.

3. Sahetya S, Goligher E, Brower R. Fifty years of research in ARDS: setting positive end expiratory pressure in acute respiratory distress syndrome. Am J Respir Crit Care Med. 2017;195:1429-38.
4. Lytle F, Brown D. Appropriate ventilatory settings for thoracic surgery: intraoperative and postoperative. Semin Cardiothorac Vasc Anesth. 2008;12:97-108.

5. Meier A, Sell RE, Malhotra A. Driving pressure for ventilation of patients with acute respiratory distress syndome. Anesthesiology. February 20, 2020 [Epub ahead of print].

6. Rubenfield G. Who cares about preventing acute respiratory distress syndrome? Am J Respir Crit Care Med. 2015;191:255-60.
See Article page 1112.

\section{Commentary: To PEEP, or not to PEEP, that is no longer a question}

\author{
Elena Ashikhmina, MD, PhD
}

Intraoperative one-lung ventilation (OLV) is in demand more than ever since it was first introduced to clinical practice in November 1949. ${ }^{1}$ Double-lumen endotracheal tubes for lung isolation are now frequently used not only for conventional thoracic surgical procedures but also for minimally invasive cardiac operations, including robotic mitral valve repairs ${ }^{2}$ and novel transcutaneous electrophysiological interventions such as convergent maze procedure. ${ }^{3}$ Thus, it is important to revisit the basics of the OLV and make sure that no harm is done to the patient while the proceduralist is getting better exposure.

In this issue of the Journal, Peel and colleagues ${ }^{4}$ present the results of a systematic review and meta-analysis of the effect of lung recruitment and positive end-expiratory pressure (PEEP) on ventilation and oxygenation during OLV. The authors performed an extensive search of existing literature only to discover that despite a vast, worldwide use of OLV, there is a paucity of studies focused on clinical rather than surrogate outcomes of the efficacy of lung-protective ventilation strategy. Meta-analysis revealed that recruitment maneuvers and PEEP have physiologic advantages during OLV. Recruitment maneuvers increased arterial oxygen tension $\left(\mathrm{PaO}_{2}\right)$ and reduced dead space, whereas PEEP was associated with improved compliance and increased

From the Department of Anesthesiology and Perioperative Medicine, Mayo Clinic, Rochester, Minn.

Disclosures: Author has nothing to disclose with regard to commercial support.

Received for publication Feb 26, 2020; revisions received Feb 26, 2020; accepted for publication Feb 26, 2020; available ahead of print March 19, 2020.

Address for reprints: Elena Ashikhmina, MD, PhD, Department of Anesthesiology and Perioperative Medicine, Mayo Clinic, 200 First St SW, Rochester, MN 55904 (E-mail: Ashikhmina.elena@mayo.edu).

J Thorac Cardiovasc Surg 2020;160:1124-5

$0022-5223 / \$ 36.00$

Copyright (c) 2020 by The American Association for Thoracic Surgery

https://doi.org/10.1016/j.jtcvs.2020.02.117
Check for updates

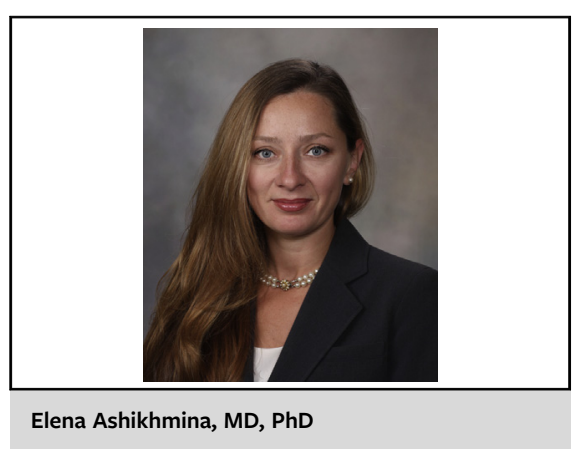

CENTRAL MESSAGE

The application of positive endexpiratory pressure and recruitment maneuvers during onelung ventilation is associated with greater $\mathrm{PaO}_{2}$, pulmonary compliance, and reduced dead space.

$\mathrm{PaO}_{2}$. However, the high risk of bias related to a small sample size and heterogeneity was identified in the majority of studies. Also, not all the potential components of lungprotective ventilation strategy for OLV were amenable for the meta-analysis. Thus, the impact of tidal volume, approach to nondependent lung ventilation/PEEP application, shunt fraction, and inspiration to expiration ratio were not assessed. Most importantly, it remains unknown if "good numbers" (greater $\mathrm{PaO}_{2}$, better compliance) were translated into better clinical outcomes (faster extubation, shorter hospital stay).

The current study was focused on the thoracic surgical population and excluded those patients who underwent cardiopulmonary bypass. However, as the lung isolation becomes more common for a broader spectrum of interventions, future studies should not omit these patients. Their number is growing, and more evidence-based 
knowledge is required to safely get them through the procedure, immediate postoperative recovery, and rehabilitation.

\section{References}

1. McGrath B, Tennuci C, Lee G. The history of one-lung anesthesia and the doublelumen tube. J Anesth Hist. 2017;3:76-86.
2. Rehfeldt KH, Andre JV, Ritter MJ. Anesthetic considerations in robotic mitral valve surgery. Ann Cardiothorac Surg. 2017;6:47-53.

3. Zannis K, Alam W, Sebag FA, Folliguet T, Bars C, Fahed M, et al. The convergent procedure: a hybrid approach for long lasting persistent atrial fibrillation ablation, the French experience. J Cardiovasc Surg (Torino). October 9, 2019 [Epub ahead of print].

4. Peel J, Funk D, Slinger P, Srinathan S, Kidane B. Positive end-expiratory pressure and recruitment maneuvers during one-lung ventilation: a systematic review and meta-analysis. J Thorac Cardiovasc Surg. 2020;160:1112-22.e3. 